\title{
1 Relationships between structural complexity, coral traits, and reef fish
}

2 assemblages

4 Emily S. Darling1,2,*, Nicholas A. J. Graham ${ }^{3,4}$, Fraser A. Januchowski-Hartley ${ }^{5}$,

5 Kirsty L. Nash ${ }^{6,7}$, Morgan S. Pratchett ${ }^{4}$ and Shaun K. Wilson ${ }^{8,9}$

6

7 1Wildlife Conservation Society, Marine Program, Bronx, NY 10460, United States

8 2Department of Ecology and Evolutionary Biology, University of Toronto, Toronto, ON, M5S

9 3B2, Canada

10 32Lancaster Environment Centre, Lancaster University, Lancaster LA1 4YQ, United Kingdom

$11{ }^{4}$ ARC Centre for Excellence for Coral Reef Studies, James Cook University, Townsville, QLD,

12 4811, Australia

13 51 UMR 9190 MARBEC, IRD-CNRS-IFREMER-UM, Universite' de Montpellier, Montpellier,

14 34095, France

$15{ }^{6}$ Centre for Marine Socioecology, Hobart, Tasmania, 7000, Australia

16 7Institute of Marine and Antarctic Studies, University of Tasmania, Hobart, Tasmania, 7000,

17 Australia

18 8Science \& Conservation, Department of Parks and Wildlife. Perth, 6983, Australia.

$19{ }^{9}$ Oceans Institute, University of Western Australia, Crawley, Western Australia, 6009,

20 Australia

21

22 *Author for correspondence: edarling@wcs.org

23 Target journal: Coral Reefs

24 Article type: Report 


\section{Abstract}

26 With the ongoing loss of coral cover and the associated flattening of reef

27 architecture, understanding the links between coral habitat and reef fishes is of

28 critical importance. Here, we investigate whether considering coral traits and

29 functional diversity provides new insights into the relationship between structural

30 complexity and reef fish communities, and whether coral traits and community

31 composition can predict structural complexity. Across 157 sites in Seychelles,

32 Maldives, the Chagos archipelago and Australia's Great Barrier Reef, we find that

33 structural complexity and reef zone are the strongest and most consistent

34 predictors of reef fish abundance, biomass, species richness, and trophic structure.

35 However, coral traits, diversity and life histories provided additional predictive

36 power for models of reef fish assemblages, and were key drivers of structural

37 complexity. Our findings highlight that reef complexity relies on living corals - with

38 different traits and life histories - continuing to build carbonate skeletons, and that

39 these nuanced relationships between coral assemblages and habitat complexity can

40 affect the structure of reef fish assemblages. Seascape-level estimates of structural

41 complexity are rapid and cost-effective with important implications for the

42 structure and function of fish assemblages, and should be incorporated into

43 monitoring programs.

44

45 Keywords: Habitat diversity, species traits, functional ecology, reef architecture,

46 Scleractinian corals, coral reef fish 


\section{Introduction}

50 Scleractinian corals - the foundation species of tropical reef ecosystems - have long

51 been recognized to provide essential habitat for reef associated organisms

52 (Luckhurst and Luckhurst 1978; Roberts and Ormond 1987; Stella et al. 2011).

53 Similarly, structural complexity, defined as the physical three-dimensional

54 configuration of a reef, can shape the abundance and diversity of reef fish

55 assemblages across both large and small spatial scales (McCormick 1994; Nash et al.

56 2012; Ferrari et al. 2016). Several ecological hypotheses are proposed to underlie

57 these relationships, notably that structural complexity and habitat diversity can

58 mediate competition and predation, and facilitate co-habitation of an increased

59 number of species (Hutchinson 1959; Hixon and Beets 1993; Beukers and Jones

60 1997).

61 Structural complexity is often positively associated with abundance and

62 diversity of fishes across both temperate and tropical ecosystems (Friedlander et al.

63 2003; Graham and Nash 2013). Moreover, reductions in structural complexity and

64 habitat diversity can result in reduced abundance, local extinctions, diversity loss

65 (Graham et al. 2006; Holbrook et al. 2015; Newman et al. 2015), and declining

66 fisheries productivity (Rogers et al. 2014); all outcomes with profound implications

67 for reef biodiversity and associated ecosystem services.

68 Despite important relationships between structural complexity and reef

69 fishes, coral reef monitoring programs typically focus on measuring total live cover

70 and composition of reef-building corals. While many relationships between coral 
71 cover and reef fish assemblages have been weaker than structural complexity

72 (Holbrook et al. 2008; Wilson et al. 2012), field experiments suggest that

73 microhabitat (i.e., coral) diversity and some coral species can have a positive effect

74 on fish diversity and community structure (Messmer et al. 2011; Holbrook et al.

75 2015). Recently, trait-based approaches have outlined important characteristics of

76 coral assemblage beyond total coral cover or taxonomic composition (Darling et al.

77 2012; Madin et al. 2016a,b), which may provide insights for predicting the structure

78 and diversity of reef fish communities. Traits that describe coral morphology,

79 growth rate and colony size may be expected to predict structural complexity, and

80 thus the structure and composition of fish assemblages. As such, coral traits may

81 provide a means of quantifying structural complexity and predicting fish

82 assemblage properties from benthic surveys where direct measures of

83 macrocomplexity were not taken, particularly in combination with the availability of

84 open-access trait information (Madin et al. 2016a,b). For example, traits that

85 describe branching, corymbose or plating growth forms can provide keystone

86 structures for reef fishes, which can preferentially select specific structural traits of

87 corals for shelter (Noonan et al. 2012; Kerry and Bellwood 2012, 2015; Wilson et al.

88 2016). A range of other explicit links can be made for other coral traits (Table 1).

89 To the best of our knowledge, this study presents the first large-scale

90 empirical test of trait-based relationships among coral communities, structural

91 complexity and reef fish assemblages. We use surveys across a large gradient of fish

92 biomass in the Indian and Pacific Oceans ranging from exploited sites to those

93 within one of the world's most pristine reef systems, the Chagos archipelago 
94 (Graham and McClanahan 2013). Our objectives were to, 1) evaluate which aspects

95 of the physical and biological characteristics of benthic habitats best explain the

96 structure of reef fish assemblages, in particular how well do coral traits describe fish

97 assemblages relative to physical measures of reef structure, and 2) investigate the

98 relationships between hard coral cover, life histories and species traits with

99 structural complexity.

100

\section{Methods}

102 Study sites

103 We surveyed 157 sites in the Seychelles, Maldives, Chagos archipelago and the Great

104 Barrier Reef in Australia between 2010 and 2013 (Figure 1). Sites were

105 haphazardly sampled across three reef zones (reef crest, flat and slope; also referred

106 to as reef habitat) and include fished sites and sites within no-take marine reserves.

107 Depth was recorded for each site and ranged from $1.5 \mathrm{~m}$ to $10 \mathrm{~m}$. At each site,

108 benthic and coral reef fish surveys were conducted using underwater visual census

109 methods to evaluate coral communities, habitat complexity and reef fish

110 assemblages.

111

112 Coral assemblages

113 Coral assemblages were surveyed using two methods: four $\mathrm{x} 50 \mathrm{~m}$ point intercept

114 transects in Chagos, Maldives and Australia, and eight $\mathrm{x} 10 \mathrm{~m}$ line intercept transects

115 in the Seychelles. For point intercept transects, the substrate directly below the

116 transect tape was surveyed every $50 \mathrm{~cm}$. For line intercept transects, the length of 
117 each substrate type was measured along the entire $10 \mathrm{~m}$ distance. For each method,

118 we recorded major benthic categories (e.g., hard coral, soft coral, sand, rubble,

119 pavement, algae, sponge, etc.) and identified hard corals to genus and growth form

120 using standard morphological genus names. These methods are typically

121 comparable (Facon et al. 2016) and here, we directly compared these methods by

122 conducting a sensitivity analysis where we re-ran our entire analysis without the

123 line intercept transects from the Seychelles and reached similar overall conclusions

124 (see Appendix 1).

125 We estimated structural complexity on each transect using a visual six-point

126 scale, following Polunin \& Roberts (1993). The scale ranges from 0 (no vertical

127 relief) to 5 (exceptionally complex habitats with numerous caves and overhangs);

128 for a full description of this scale and pictures, see Appendix 2. This measure of

129 structural complexity has been shown to correlate well with a range of other

130 structural complexity measurement techniques (Wilson et al. 2007), to strongly

131 predict coral and reef fish diversity (Polunin and Roberts 1993; Chong-Seng et al.

132 2012; Newman et al. 2015), and reef recovery following mass bleaching events

133 (Graham et al. 2015). All visual observations of structural complexity were recorded

134 by one observer, NAJG. This method has also been shown to quickly provide a

135 reliable and effective estimate of habitat complexity, with regular training of

136 multiple observers limiting observer bias (Wilson et al. 2007).

137 We derived 17 metrics of coral communities based on benthic surveys,

138 including total cover of scleractinian corals, genera richness, percent cover of life 
139 histories, and abundance-weighted trait means and functional diversity (Table 1).

140 Total coral cover was estimated as the average percent of living hard coral at each

141 site, and genera richness was estimated as the average number of coral genera on

142 replicate transects. Richness was estimated from raw estimates and not adjusted by

143 rarefaction after a post-hoc sensitivity analysis of two underwater survey methods

144 revealed similar conclusions (Appendix 1). Life histories were evaluated based on

145 the abundance (percent cover) of four life-history groups - competitive, stress-

146 tolerant, weedy and generalist corals - proposed by Darling et al. (2012), which

147 have revealed community shifts in response to various disturbances on coral reefs

148 (Darling et al. 2013; Graham et al. 2014; Sommer et al. 2014). The functional

149 structure of coral assemblages was evaluated by five traits that define the life

150 histories reported in Darling et al. (2012): colony growth form (branching, plating

151 or domed), maximum colony size, growth rate (measured as annual linear

152 extension, $\mathrm{mm}$ year-1 ${ }^{-1}$ ), reproductive mode (brooding or broadcast spawning) and

153 fecundity. These five coral traits were selected because they had tangible links to

154 reef fish assemblages; see Table 1 for detailed justification. A full list of observed

155 hard corals, growth forms and their associated traits can be found in Supporting

156 Table S1; trait information is also freely available online at https://coraltraits.org

157 (Madin et al. 2016a). To estimate genus-level trait values, we averaged available

158 trait information for species that occurred in the appropriate Indo-Pacific faunal

159 province, based on Keith et al. (2013) (Africa-India province: Chagos, Maldives and

160 Seychelles; Australian province: Great Barrier Reef). For categorical traits (colony

161 growth form and reproductive mode), we calculated the proportion of species in 
162 each genus with the trait (see Table S1). Six genera (Heliopora, Millepora,

163 Oulaphyllia, Polyphyllia, Tubastrea, Tubipora) were removed from life history and

164 trait analyses because of limited trait information (and these genera had limited

165 abundances within our surveyed coral communities).

166 To derive multivariate measures of functional diversity, we conducted a

167 principal components analysis (PCoA) on the five coral traits using a Gower

168 dissimilarity matrix. We then estimated two measures of functional diversity:

169 functional richness and Rao's quadratic entropy. Functional richness was derived

170 from the number of distinct functional groups in a community based on a Ward's

171 clustering analysis, and Rao's quadratic entropy was measured from the average

172 distance of abundance-weighted maximum pairwise-distances in functional space at

173 each site (Mouillot et al. 2013). At each site, we calculated a community-weighted

174 trait mean for each of the five traits by weighting the values of each trait by the

175 relative abundance of corals (Mouillot et al. 2013). Overall, our approaches estimate

176 three unique components of traits and functional diversity to consider, a) functional

177 richness of trait combinations (FunctionalRichness), b) functional entropy of a

178 community (FunctionalRao), and c) abundance-weighted trait values for five traits.

179 We used the package "FD" in R for all functional analyses (Laliberté and Legendre

180 2010).

181

182 Reeffish assemblages

183 We estimated the density and individual sizes of all species of diurnally active, non-

184 cryptic, reef associated fish $>8 \mathrm{~cm}$ total length at each site using two comparable 
185 methods. In the Seychelles, eight replicate $7 \mathrm{~m}$ radius point counts were conducted 186 at each site $\left(154 \mathrm{~m}^{2} /\right.$ replicate); all other locations used four replicate $50 \mathrm{~m} \times 5 \mathrm{~m}$

187 belt transects $\left(250 \mathrm{~m}^{2} /\right.$ replicate $)$ for large and mobile fishes, while smaller and site188 attached, territorial species (e.g., pomacentrids) were recorded using four replicate $18950 \mathrm{~m} \times 2 \mathrm{~m}$ belt transects $\left(100 \mathrm{~m}^{2} /\right.$ replicate $)$. For each transect, we calculated the 190 total numerical abundance, biomass and species richness of reef fish assemblages

191 and averaged these values at each site. All estimates were standardized to 192 estimates $/ 250 \mathrm{~m}^{2}$ for comparison across sites. As described in the benthic analyses,

193 we conducted a sensitivity analysis to account for these different methodologies by

194 re-running analyses with and without the Seychelles dataset, which revealed very

195 similar findings to the full dataset analysis; while there is some influence of survey

196 methods on the list of variables in the top models, overall our main findings and

197 conclusions are supported (Appendix 1). We also included fish method (point count

198 vs. belt transect) as a variance-covariate in the model framework to account for

199 uneven variation across methods (see Data Analysis below). Total reef fish

200 abundance was strongly correlated to the numerical abundance of small fish $[<20$

$201 \mathrm{~cm}$; general linear model $\left.\mathrm{R}^{2}=0.85, \mathrm{p}<0.001\right)$, and we modelled both total

202 abundance and the abundance of small fish $<20 \mathrm{~cm}$ in separate analyses. This

203 allowed us to model the abundance of both the overall fish assemblage and juvenile

204 or small-bodied fish that are often more associated with the reef habitat (Beets and

205 Hixon 1989; Bergman et al. 2000; Graham et al. 2007; Wilson et al. 2010). Reef fish

206 biomass was calculated using standard length-weight conversions and diversity was

207 estimated from species richness as the total number of species observed at each site. 
208 Fish species were assigned to the following trophic (feeding) groups, following

209 Graham et al. (2006): corallivores, herbivories, invertivores, mixed-diet feeders,

210 piscivores and planktivores. The link between these feeding groups and specific

211 characteristics of the coral assemblage may be expected to be stronger than for total

212 biomass.

214 Data analysis

215 For all analyses, we used multi-model averaging of mixed-effects linear models with

216 maximum likelihood estimation to evaluate relationships between coral

217 assemblages, structural complexity and reef fish communities. We evaluated all

218 variables described above for multicollinearity, and found, not surprisingly, that

219 coral life histories were strongly correlated with coral cover. Therefore we

220 conducted two similar analyses: one with life histories and one with coral cover (see

221 Appendix 3). Our final variable set consisted of independent predictors with

222 variance inflation factors $<5$, following Zuur et al. (2010)(Table 1) - notably growth

223 rate was removed from the candidate set of traits due to multicollinearity (VIF > 5;

224 Table 1). Using mixed-effects general linear models, we first evaluated the effects of

225 coral diversity (genera richness), traits, life histories and structural complexity on

226 reef fish abundance, biomass and diversity, followed by a second analysis that

227 evaluated the effects of coral diversity, traits and life histories on structural

228 complexity. All models were repeated by replacing the four coral life histories with

229 total coral cover, to address issues of multicollinearity between life histories and 
230 coral cover, as discussed above. Total biomass and biomass for the six trophic 231 groups of fishes were log-transformed in all models.

232 All models included a random effect of country, whereby sites were nested 233 within country to account for biogeographic differences of latitude, large-scale 234 environmental conditions, and differences in fishing pressure among the countries 235 studied (see equation: site $j$ in country $i$ ). We also applied residual variance

236 structures to account for identifiable structure in the error residuals of our full

237 model. Variance structures are variables used to model the structure of the

238 residuals, without a penalty of adding more model parameters (Zuur et al. 2009).

239 We used AIC to compare variance structures and identify which one performed

240 better in all models. For all models, a varIdent variance structure was applied to

241 account for uneven residual error within management groups (marine reserve vs.

242 open access) and fish methods (belt transect vs. point count). For fish abundance,

243 we also applied a varPower variance structure to habitat complexity that accounted

244 for greater observed residual variation in more complex habitats; this error

245 structure was not required for the biomass or diversity models, although we did

246 apply it in models for the six trophic groups. We also tested a varIdent variance

247 structure for coral method (point count vs. line intercept), which did not improve

248 model fit in the fish models, but did improve fit in the analysis of structural 249 complexity.

$250 \quad$ For the analysis of reef fish assemblages, we applied the following model 251 structure to reef fish abundance, biomass, species richness and trophic groups: 
Fish response $_{i j}=\beta_{0}+\beta_{1} \times$ Reef zone $_{i j}+\beta_{2} \times$ Depth $_{i j}+\beta_{3} \times$ Management $_{i j}$ $+\beta_{4} \times$ Complexity $_{\mathrm{ij}}+\beta_{5} \times$ GeneraRichness $_{\mathrm{ij}}+\beta_{6} \times$ FunctionalRao $_{\mathrm{ij}}$

$$
+\beta_{7} \times \text { CoralBranching }_{i j}+\beta_{8} \times \text { CoralMaxSize }_{i j}
$$$$
+\beta_{9} \times \text { CoralBrooding }_{i j}+\beta_{10} \times \text { CoralFecundity }_{i j}
$$

Prior to analysis, all input variables were centered to a mean of zero and

262 standardized to a standard deviation of \pm 1 , in order to allow for direct comparisons 263 of variable effect sizes (in R, function 'rescale' in package arm; Gelman 2008). For 264 each fish response, we evaluated 3473 models by completing every combination of 265 variables (up to 5 variables per model) and comparing models using Akaike's

266 Information Criteria corrected for small sample size (AICc) (Akaike 1974). Within a

267 top model set of $4 \Delta \mathrm{AIC}_{\mathrm{c}}$ of the best model, we calculated model-averaged

268 coefficients and 95\% confidence intervals; significant coefficients were identified

269 from confidence intervals that did not overlap zero. We also calculated the variable

270 importance for each coefficient as the sum of Akaike weights across all models,

271 which provided a rank for each variable, where a relative variable importance of 1.0

272 identifies the highest ranked input variable (Burnham and Anderson 2002). For

273 model validation we assessed the heterogeneity and normality of residuals across

274 the top 95\% set of candidate models. We fit all models in the package nlme (Pinheiro 
275 et al. 2015) with multi-model averaging using the package MuMin (Bartoń 2016); all 276 analyses were conducted in R (R Core Team 2015).

277 We applied the same statistical approach to model structural complexity 278 using characteristics of coral diversity, traits and life histories. Here, 2380 models 279 were evaluated using every possible combination (up to 5 variables) with a random 280 effect of country and a variance-covariate varIdent structure applied to 281 management and coral method. The model structure was defined as:

290 As described above, all input variables were centered and standardized to a mean of 291 zero \pm 1 standard deviation prior to analysis, and we conducted the same multi292 model inferences using Akaike's information criteria.

\section{Results}

295 Structural complexity and reef zone were the strongest predictors of reef fish 296 abundance, biomass, diversity and trophic structure across $\sim 38,000$ mixed-effects 297 models. Structural complexity was a consistently top-ranked predictor in all models 298 of reef fish assemblages (i.e., with a maximum relative variable importance of $1.0 \mathrm{in}$ 
299 all model comparisons (Table 2; Appendices 3-6). Characteristics of reef zone and 300 depth also revealed high variable importance for abundance and diversity, but not

301 biomass; slope and crest zones were typically associated with more abundant and 302 diverse reef fish communities than reef flats (Table 2; Fig. 2a-c).

303 Management (marine reserve vs. open access), coral cover and genera

304 richness, functional diversity, species traits of colony size and branching and some

305 life histories were also associated with different characteristics of reef fish

306 assemblages, including the abundance of small fishes and trophic groups (Table 2;

307 Fig. 2; Fig. 3; Appendices 3-6). Total reef fish abundance decreased with depth and 308 functional diversity, and increased with more complex habitats, cover of stress-

309 tolerant corals and slope zones (Fig. 2a); these patterns were consistent for the

310 abundance of smaller fish $<20 \mathrm{~cm}$, which also included weaker effects of life

311 histories, coral traits, genera richness and management variables in the top models

312 (Appendix 4), although complexity only appeared in two of the top 11 models for

313 smaller fish abundance and had a lower relative importance than aforementioned

314 variables. Reef fish biomass increased with structural complexity within no-take

315 reserves and, across all management types, with greater cover of stress-tolerant

316 corals, and decreased cover of weedy corals (Fig. 2b). Species richness was greater

317 at sites within slope and crest habitats, with higher complexity, and characterized

318 by larger maximum colony size. In addition, a suite of life histories, traits, depth and

319 management had weaker influences, i.e., with 95\% confidence intervals overlapping

320 zero and lower relative variable importance (Table 2; Fig. 2c). Overall, total

321 abundance and biomass were predicted by fewer variables (5-6 in top models) than 
322 the abundance of smaller fish and diversity, which included 15 variables in each top 323 model set (Appendix 4).

324 The biomass of reef fish trophic groups also included structural complexity 325 as a main driver in each analysis, whereby sites with more complex reef structure

326 were associated with greater biomass of each trophic group (Fig. 3; Appendix 5).

327 Each trophic group was predicted by a different suite of traits, life histories and

328 other variables; for example, the biomass of corallivores increased with the

329 abundance of competitive branching and plating corals and with depth (Fig. 3a),

330 while the biomass of piscivores increased with depth and management, in addition

331 to a suite of weaker trait and life history variables (Fig. 3e).

332 We also separated out the effects of management in these relationships by

333 conducting separate analyses of total reef fish biomass within no-take marine

334 reserves vs. open access fished reefs (Appendix 6). This revealed that the influence

335 of complexity, life histories, traits and habitat on total biomass within marine

336 reserves was more complex (i.e., 7 top variables) than on fished reefs, where

337 biomass was predicted by complexity and a weaker influence of coral genera

338 richness (Fig. S6-1).

339 Structural complexity was predicted by a large suite of benthic and habitat

340 characteristics, including hard coral traits and life histories (Fig. 4). Habitat and the

341 abundance of competitive, stress-tolerant and generalist life histories, genera

342 richness, and traits of colony size, branching and fecundity were the strongest

343 predictors of structural complexity and had the highest relative variable importance

344 in the top 95\% model set after evaluating 3,000 mixed-effects models (Fig. 4, Table 
345 3). Structural complexity was typically higher on the reef slope and crest than reef

346 flat and increased with percent cover of competitive and generalist corals, genera

347 richness, and maximum colony size; structural complexity was lower on reefs with a

348 high abundance of corals with branching traits and high fecundity (Fig. 3b). Coral

349 cover was also a significant and positive predictor of structural complexity; sites

350 with higher coral cover were associated with higher structural complexity

351 (Appendix 3).

352

353 Discussion

354 Understanding the associations between habitat structure and reef fishes and

355 mobile invertebrates has been a key focus of coral reef ecology for decades

356 (Luckhurst and Luckhurst 1978; Roberts and Ormond 1987; Stella et al. 2011).

357 Recently, trait-based metrics for both corals (Darling et al. 2012; Madin et al. 2016b)

358 and reef fishes (Mouillot et al. 2013) have been proposed to offer new insights into

359 patterns of diversity and function on coral reefs in order to provide a more

360 mechanistic understanding of associations between benthic characteristics and fish

361 assemblages. Here, we show that the abundance, biomass, diversity, and trophic

362 structure of diurnal, non-cryptic reef fishes were strongly and consistently

363 predicted by structural complexity and reef zone while characteristics of hard coral

364 traits, total cover, life histories, and functional diversity added subtle, if weaker,

365 effects to these relationships (Table 2; Fig. 2). Importantly, hard coral

366 characteristics of total cover, traits and life histories, strongly influenced structural

367 complexity (Table 3; Fig. 3), which highlights the indirect relationships by which 
368 living hard corals can provide structural complexity and habitat diversity for reef

369 fishes.

370 The consistent influence of structural complexity and reef zone emphasize

371 the importance of both living and non-living components of the reef that can

372 structure reef fish assemblages. For examples, we show that the living 'veneer'

373 provided by live hard corals and their associated traits, diversity and life histories

374 can also influence reef fish assemblages and contributes critically to structural

375 complexity. Interestingly, different characteristics of the coral assemblage

376 contributed to different components of the reef fish assemblage. Coral genera

377 richness and functional diversity appeared in the top model sets for total biomass

378 and diversity, the abundance of small fish, and the biomass of herbivores, piscivores

379 and planktivores, yet were mainly weak variables compared to the influence of

380 complexity and habitat. Similarly, coral life histories and traits influenced total

381 abundance, biomass and diversity, the abundance of small fish, and the biomass of

382 corallivores, mixed-diet feeders, piscivores and planktivores but were also typically

383 weaker predictors (Figs. 2-3, Appendices 4-5). Thus, we conclude that the

384 mechanistic hypotheses that coral diversity, life histories and traits support the

385 structure of reef fish assemblages is only weakly supported (e.g., Table 1), compared

386 to the stronger influences of overall structural complexity and reef zone. It should

387 be noted, however, that the reef fish community was only surveyed $>8 \mathrm{~cm}$ in length.

388 It is possible that smaller fishes would show a stronger relationship with some coral 389 growth forms, such as branching corals. 
391 influenced by more variables than others: notably species richness, the abundance

392 of smaller individuals (between 8 and $20 \mathrm{~cm}$ ) and the biomass of piscivores and

393 planktivores, with $>10$ variables in the top model set (Fig. 2-3, Appendix 4). This

394 suggests that different types of living corals and their traits influence different

395 components of reef fish assemblages, as well as provide important habitat for the

396 abundance of all fishes and smaller juvenile fish recruits even when adults of their

397 species may have less affinity for live corals (Jones et al. 2004). Clearly, there are

398 many complex and indirect interdependencies between reef corals and reef fishes

399 that require further investigation (Pratchett et al. 2015), and a combination of

400 structural complexity and living corals is likely required for optimal reef fish

401 productivity and diversity.

402 Overall, the strong influence of seascape-level structural complexity on reef

403 fish assemblages may be because this index integrates both living hard corals and

404 non-living features of the reef matrix such as caves, crevices or overhangs that can

405 reflect reef growth and erosion processes accumulated over decades, centuries or

406 even millennia (Kleypas et al. 2001; Appendix 2). Thus, the reef matrix can provide

407 some resilience to disturbances that directly confer mortality to living corals (e.g.,

408 bleaching and outbreaks of crown-of-thorns starfish), which may also explain why

409 fish diversity can be maintained following extensive coral mortality on inherently

410 complex reefs (Wilson et al 2009; Graham et al. 2015). However, we have shown

411 that various aspects of the living corals are critical to providing structural

412 complexity, and likely maintaining it in the long run. However, the seascape metric 
413 of structural complexity we used does not capture small-scale complexity, such as

414 the presence of small holes $<10 \mathrm{~cm}$ (Wilson et al. 2007), and our surveys focus on

415 fish $>8 \mathrm{~cm}$, which limits our ability to make inferences about the how smaller fish

416 use finer-scale structural complexity (e.g., smaller spaces within branching coral

417 colonies).

418 No-take marine reserves were also, unsurprisingly, a key factor in predicting

419 total reef fish biomass (e.g., MacNeil et al. 2015). This suggests that strategically

420 locating marine reserves or fisheries management (e.g., gear restrictions) in areas

421 with structurally complex reefs may provide greater returns on investments for

422 biomass recovery than if focused on low complexity reefs (McClanahan et al. 2011;

423 MacNeil et al. 2015). Piscivore biomass was greater in reserves and there were more

424 complex associations between habitat and coral traits in reserves compared to

425 fished reefs, which showed much simpler relationships. This supports well-

426 described evidence that overexploitation of fish can weaken predator-prey

427 processes, and decouple biophysical relationships (Madin 2010; Houk \& Musburger

428 2013; Williams et al. 2015).

429 Here, our analysis of reef fish assemblages focused on site-level variables of

430 habitat zonation and exposure and not broad biogeographic gradients of wave

431 exposure or other environmental variables (e.g., currents, bleaching or cyclone

432 disturbances). For example, wave-induced water motion and flow velocity has been

433 shown to structure the distribution and functional structure of reef fishes on Lizard

434 Island (Fulton \& Bellwood 2005). Similarly, our correlative study did not consider

435 how reef fish behavior - e.g., swimming ability and the use of flow or habitat refuges 
436 - might affect these patterns (Johansen et al. 2008). However, our findings are in

437 agreement with experimental studies on how reef fish use benthic habitat space, for

438 example the finding that Acropora table corals can provide keystone structure for

439 large reef fishes (Kerry \& Bellwood 2012; 2015) and field observations that show

440 tight links between specific coral and fish species (Cocker et al 2014). Clearly,

441 controlled experimental studies will be necessary to understand the relationships

442 between coral traits, life histories and diversity that we have investigated here using

443 field-based surveys and correlative analyses.

$444 \quad$ Hard coral assemblages strongly influenced structural complexity - sites

445 with higher coral cover, greater genera richness, more abundant competitive and

446 generalist life histories, and traits of larger colony sizes and higher growth rates

447 were associated with more complex reefs (Table 3; Fig. 4; Supporting Appendix 3).

448 Surprisingly, the abundance of corals with branching traits was negatively

449 associated with structural complexity (Fig 3). This is a contrasting finding to studies

450 that have found a positive association between the abundance of branching corals

451 and fish assemblages via structural complexity (Chabanet et al. 1997; Messmer et al.

452 2011; Graham and Nash 2013). This may, perhaps, be because the refuge spaces

453 associated with many fine branching corals are small $(<10 \mathrm{~cm})$ and this scale of

454 complexity is not well captured by the visual assessments of structural complexity

455 used here (Wilson et al. 2007). In addition, the dominance of corals with branching

456 traits may also create a homogeneous habitat that might reduce the overall

457 structural complexity of a reef. Alternatively, coral identities (i.e., specific genera) or

458 life histories may be a better predictor of structural complexity than the individual 
459 coral traits investigated in this analysis. For example, the cover of competitive life

460 histories (typically branching and plating acroporiids, Darling et al. 2012) was

461 positively associated with structural complexity, as was the number of coral genera.

462 Previous studies have also found strong relationships between specific genera with

463 structural complexity; for example, large, massive Montastrea (now Orbicella)

464 colonies are associated with greater structural complexity (Alvarez-Filip et al. 2011)

465 while the cover of branching Pocillopora was negatively related to reef complexity

466 (Perry et al. 2015). However, as the new systematics of Scleractinia continue to

467 inform and revise morphological classifications (e.g., Kitihara et al. 2016), trait

468 selection and inference must carefully consider how traits are matched to genera

469 observed on monitoring surveys.

$470 \quad$ While structural complexity and reef zonation are known to be major drivers

471 of reef fish assemblages (Wilson et al. 2009; Graham and Nash 2013), here we show

472 that coral traits and diversity can also have subtle effects on these relationships, as

473 well as being key variables in determining structural complexity. This suggests that

474 the long term maintenance and production of future structural complexity on

475 carbonate reefs will rely on living hard corals continuing to build the carbonate

476 framework of reefs since dead corals inevitably break down and erode.

477 Furthermore, this emphasizes the importance of past disturbance histories and

478 recovery trajectories, particularly as disturbed coral assemblages shift in

479 composition towards smaller weedier or opportunistic species that may provide

480 less complexity overall (Darling et al. 2013; Alvarez-Filip et al. 2013). 
As trait-based approaches move to advance coral reef science (Madin et al.

482 2016a,b), our study highlights two important caveats and considerations for future

483 trait-based investigations. First, coral traits may have weak associations with reef

484 fish assemblages, even if these traits are mechanistically associated with ecosystem

485 processes of interest (e.g., growth forms, colony size or growth rates). Here, the five

486 traits used in this analysis had general relevance for fish community structure,

487 although considering different traits, such as inter-colony volume, actual colony

488 size, or volume under colonies, may have resulted in stronger relationships and

489 different conclusions. Traits might also be explicitly tied to reef fish processes

490 through specific links to energy production or shelter provisioning, however

491 empirical data on these processes is typically limited and may require additional

492 experimental (e.g., Kerry \& Bellwood 2012; 2015) or modeling approaches (e.g.,

493 biomass spectrum models or size-based theory; Trebilco et al. 2013). Second, most

494 species-level coral trait information is largely available only as global averages,

495 which does not reflect regional or intra-specific variation in coral traits. Given that

496 intraspecific variation in coral morphology influences associations between fishes

497 and host corals (e.g., Noonan et al. 2012), this will limit the usefulness of trait

498 information when averaged up to the genera level (the common taxonomic

499 resolution of most underwater coral surveys). Here, we used genus-level trait

500 averages estimated from regionally appropriate species lists (the Indo-Pacific faunal

501 provinces of Keith et al. 2013), yet we still find relatively weak associations between

502 traits and coral reef fish assemblages. Evaluating the coral traits of specific colonies

503 (vs. species or genus-level averages) may yield stronger relationships, although this 
504 requires significantly more field effort which is logistically challenging for regional

505 or global comparisons (Coker et al. 2014). However, we also find that simple life

506 history groups based on species traits (from Darling et al. 2012) are useful

507 predictors of structural complexity, which suggests that even coarse groupings of

508 life history traits may have some utility in describing reef functions, such as

509 structural complexity and the trophic structure of reef fish assemblages. Overall, the

510 availability of new, open-access databases can aggregate and provide trait

511 information online to test these hypotheses in the future (Madin et al. 2016a)

512

\section{Conclusions}

514 An obvious symptom of reef degradation is the transition towards net

515 erosion, due to declines in reef accretion caused by declines in abundance and/ or

516 growth of calcifying organisms, and especially scleractinian corals (Kleypas et al.

517 2001; Alvarez-Filip et al. 2009; Perry et al. 2013). Maintaining key demographic

518 processes of coral growth and carbonate accretion will be increasingly important to

519 maintain structural complexity and habitat diversity for reef fishes and

520 invertebrates. However, this is a challenging recommendation for managers and

521 decision makers in the context of increasing local stressors, ocean warming and

522 acidification, and sea level rise (Hoegh-Guldberg et al. 2007; Manzello et al. 2008;

523 DeCarlo et al. 2015). Identifying relationships and thresholds between key

524 demographic processes and specific management actions (like water clarity or the

525 biomass of herbivorous fishes) remains a key focus for future research.

526 Furthermore, ongoing coral community shifts towards stress-tolerant, weedy and 
527 low complexity species may superficially maintain coral cover while silently

528 masking declines in complexity, coral accretion, and ecosystem services (Alvarez-

529 Filip et al. 2013; Rogers et al. 2014).

$530 \quad$ Monitoring reef condition requires indicators that capture key processes and

531 early signs of decline (Hughes et al. 2010; McClanahan et al. 2011). Here, we show

532 that seascape visual estimates of structural complexity can be easily incorporated

533 into monitoring and management programs (see Appendix 2 for more details).

534 Interestingly, this method could also be calculated retrospectively from underwater

535 images that provide a panoramic view about transects (Wilson et al. 2009), or with

536 machine-learning methods applied to satellite images or digital reef terrain maps,

537 which would allow this methodology to scale up beyond SCUBA-based surveys to

538 larger temporal and spatial scales (e.g., Pittman et al. 2009). For example, including

539 a panoramic assessment at the start and end of the transect line that includes

540 geomorphological reef features like caves or overhangs can provide important

541 assessments of structural complexity relevant to fishes (e.g., Collins et al. 2016).

542 Further, while our study is based on observations, our results are supported by

543 experimental studies that have manipulated structural complexity and specific

544 habitats (e.g., the space below tabulate corals) to reveal the importance of

545 complexity for reef fishes (Beets and Hixon 1989; Syms and Jones 2000; Gratwicke

546 and Speight 2005; Kerry and Bellwood 2012, 2015). Overall, incorporating a

547 standard measure of structural complexity into long-term monitoring programs

548 may provide useful information on the loss of reef architecture and knock-on effects

549 for coral reef ecosystems (e.g. Graham et al. 2015). 
$550 \quad$ Continued declines in the three-dimensional complexity and coral diversity

551 of tropical reefs will have consequences for reef fishes, fisheries and the human

552 societies that depend on these ecosystem services (Alvarez-Filip et al. 2013; Hicks \&

553 Cinner 2014; Rogers et al. 2014). Here, we highlight the importance of structural

554 complexity as well as the more nuanced and subtle influences of coral traits and

555 functional diversity on reef fishes. Maintaining structural complexity and coral

556 diversity should be a key focus for managers, because it can help reefs recover to a

557 coral-dominated state after mass bleaching (McClanahan et al. 2012; Graham et al.

558 2015) and supports fish diversity and fisheries productivity (Rogers et al. 2014;

559 Holbrook et al. 2015). Managing for structural complexity may include prioritizing

560 conservation and no-take reserves to, i) reefs with high existing complexity and

561 abundant live corals, such as including reef slopes with high complexity, or ii) reefs

562 where the underlying complexity is not so reliant on the accretion of reef by living

563 corals (e.g. granitic reefs) (Harris et al. 2014). Management should also reduce

564 activities that directly damage reef structural complexity or coral functional

565 diversity, such as destructive fishing gears (dynamite, drag nets, some traps),

566 physical damage by tourists, and boat anchoring. Here, we have highlighted the

567 utility of a simple and standardized methodology for assessing large-scale patterns

568 reef complexity, as well as the need to understand the subtler effects of hard coral

569 traits and diversity, to meet the future challenges of monitoring a changing

570 ecosystem.

571

572 Acknowledgements 
573 We thank Sally Keith for providing species lists for Indo-Pacific provinces. ESD was

574 supported by a David H. Smith Conservation Research Fellowship from the Cedar

575 Tree Foundation, a Banting Fellowship from the Natural Sciences and Engineering

576 Research Council of Canada, and the John D. and Catherine T. MacArthur

577 Foundation. NAJG was supported by the Australian Research Council and a Royal

578 Society University Research Fellowship. Field work in the Seychelles was supported

579 by the Seychelles Fishing Authority, Seychelles National Parks Authority, Nature

580 Seychelles, and Global Vision International. We thank the reviewers and Editor for

581 suggestions that substantially improved earlier versions of this manuscript.

582

583

584 References

585 Akaike H (1974) A new look at the statistical model identification. Autom. Control.

586 IEEE Trans. 19:716-723

587 Alvarez-Filip L, Carricart-Ganivet JP, Horta-Puga G, Iglesias-Prieto R (2013) Shifts in

588 coral-assemblage composition do not ensure persistence of reef functionality.

589 Sci. Rep. 3:3486

590 Alvarez-Filip L, Dulvy NK, Gill JA, Cote IM, Watkinson AR (2009) Flattening of

591 Caribbean coral reefs: region-wide declines in architectural complexity. Proc. R.

$592 \quad$ Soc. B Biol. Sci. 276:3019-3025

593 Bartoń K (2016) MuMIn: Multi-Model Inference. R package version 1.15.6.

594 http://CRAN.R-project.org/package=MuMIn.

595 Beets J, Hixon M (1989) Shelter characteristics and Caribbean fish assemblages: 
596 experiments with artificial reefs. Bull. Mar. Sci. 44:666-680

597 Bergman K, Ohman M, Svensson S (2000) Influence of habitat structure on

598 Pomacentrus sulfureus, a western Indian Ocean reef fish. Environ. Biol. Fishes $599 \quad 59: 243-252$

600 Beukers JS, Jones GP (1997) Habitat complexity modifes the impact of piscivores on 601 a coral reef fish population. Oecologia 114:50-59

602 Bridge TCL, Hughes TP, Guinotte JM, Bongaerts P (2013) Call to protect all coral 603 reefs. Nat. Publ. Gr. 3:528-530

604 Burnham KP and D Anderson (2002) Model selection and Multimodel Inference: A 605 Practical Information-Theoric Approach. Springer, New York, NY. 488 pp.

606 Chabanet P, Ralambondrainy H, Amanieu M, Faure G, Galzin R (1997) Relationships 607 between coral reef substrata and fish. Coral Reefs 16:93-102

608 Chong-Seng KM, Mannering TD, Pratchett MS, Bellwood DR, Graham NAJ (2012) The 609 Influence of Coral Reef Benthic Condition on Associated Fish Assemblages. PLoS $610 \quad$ One $7:$ e42167

611 Coker DJ, Wilson SK, Pratchett MS (2014) Importance of live coral habitat for reef 612 fishes. Rev. Fish Biol. Fish. 24:89-126

613 Collins DL, Langlois TJ, Bond T, Holmes TH, Harvey ES, Fisher R, McLean DL (2016)

614 A novel stereo - video method to investigate fish-habitat relationships.

615 Methods in Ecology and Evolution, in press. DOI: 10.1111/2041-210X.12650. 616 Darling ES, Alvarez-Filip L, Oliver TA, Mcclanahan TR, Côté IM (2012) Evaluating 617 life-history strategies of reef corals from species traits. Ecol. Lett. 15:1378$618 \quad 1386$ 
619 Darling ES, McClanahan TR, Côté IM (2013) Life histories predict coral community

620 disassembly under multiple stressors. Glob. Chang. Biol. 19:1930-1940

621 DeCarlo TM, Cohen AL, Barkley HC, Cobban Q, Young C, Shamberger KE, Brainard

622 RE, Golbuu Y (2015) Coral macrobioerosion is accelerated by ocean

623 acidification and nutrients. Geology 43:7-10

624 Done TJ (1982) Patterns in the distribution of coral communities across the central

625 Great Barrier Reef. Coral Reefs 1:95-107

626 Facon M, Pinault M, Obura D, Pioch S, Pothin K, Bigot L, Garnier R, Quod J (2016) A

627 comparative study of the accuracy and effectiveness of Line and Point Intercept

628 Transect methods for coral reef monitoring in the southwestern Indian Ocean

629 islands. Ecol. Indic. 60:1045-1055

630 Ferrari R, McKinnon D, He H, Smith R, Corke P, González-Rivero M, Mumby P,

631 Upcroft B (2016) Quantifying multiscale habitat structural complexity: a cost-

632 effective framework for underwater 3D modelling. Remote Sens. 8:113

633 Friedlander AM, Brown EK, Jokiel PL, Smith WR, Rodgers KS (2003) Effects of

634 habitat, wave exposure, and marine protected area status on coral reef fish

635 assemblages in the Hawaiian archipelago. Coral Reefs 22:291-305

636 Fulton CJ, Bellwood DR, Wainwright PC (2005) Wave energy and swimming

637 performance shape coral reef fish assemblages. Proc. R. Soc. B Biol. Sci. 272:

$638 \quad 827-832$.

639 Gelman A (2008) Scaling regression inputs by dividing by two standard deviations.

$640 \quad$ Statistics in Medicine 27: 2865-2873

641 Graham NAJ, Chong-Seng KM, Huchery C, Januchowski-Hartley FA, Nash KL (2014) 
642 Coral Reef Community Composition in the Context of Disturbance History on

643 the Great Barrier Reef, Australia. PLoS One 9:e101204

644 Graham NAJ, Jennings S, MacNeil MA, Mouillot D, Wilson SK (2015) Predicting

645 climate-driven regime shifts versus rebound potential in coral reefs. Nature $646 \quad 518: 94-97$

647 Graham NAJ, McClanahan TR (2013) The Last Call for Marine Wilderness?

$648 \quad$ Bioscience 63:397-402

649 Graham NAJ, Nash KL (2013) The importance of structural complexity in coral reef 650 ecosystems. Coral Reefs 32:315-326

651 Graham NAJ, Wilson SK, Jennings S, Polunin NVC, Bijoux JP, Robinson J (2006)

652 Dynamic fragility of oceanic coral reef ecosystems. Proc. Natl. Acad. Sci. U. S. A. $653 \quad 103: 8425-8429$

654 Graham NAJ, Wilson SK, Jennings S, Polunin NVC, Robinson J, Bijoux JP, Daw TM

655 (2007) Lag effects in the impacts of mass coral bleaching on coral reef fish,

656 fisheries, and ecosystems. Conserv. Biol. 21:1291-1300

657 Gratwicke B, Speight MR (2005) The relationship between fish species richness,

658 abundance and habitat complexity in a range of shallow tropical marine

659 habitats. J. Fish Biol. 66:650-667

660 Harris A, Wilson S, Graham N, Sheppard C (2014) Scleractinian coral communities of 661 the inner Seychelles 10 years after the 1998 mortality event. Aquat. Conserv.

662 Mar. Freshw. Ecosyst. 24:667-679

663 Hicks CC, Cinner JE (2014) Social, institutional, and knowledge mechanisms mediate 664 diverse ecosystem service benefits from coral reefs. PNAS 111:17791-17796 
665 Hixon M, Beets J (1993) Predation, prey refuges, and the structure of coral reef fish 666 assemblages. Ecol. Monogr. 63:77-101

667 Hoegh-Guldberg O, Hooten AJ, Steneck RS, Greenfield P, Gomez E, Harvell CD, Sale 668 PF, Edwards AJ, Caldeira K, Knowlton N, Eakin CM, Iglesias-Prieto R, Muthiga N, 669 Bradbury RH, Dubi A, Hatziolos ME (2007) Coral reefs under rapid climate 670 change and ocean acidification. Science 318:1737-1742

671 Holbrook SJ, Schmitt RJ, Brooks AJ (2008) Resistance and resilience of a coral reef 672 fish community to changes in coral cover. Mar. Ecol. Prog. Ser. 371:263-271 673 Holbrook SJ, Schmitt RJ, Messmer V, Brooks AJ, Srinivasan M, Munday PL, Jones GP 674 (2015) Reef fishes in biodiversity hotspots are at greatest risk from loss of coral $675 \quad$ species. PLoS One 10:e124054

676 Houk P, Musburger C (2013) Trophic interactions and ecological stability across 677 coral reefs in the Marshall Islands. Mar Ecol Prog Ser 488: 23-34

678 Hughes TP, Graham NAJ, Jackson JBC, Mumby PJ, Steneck RS (2010) Rising to the 679 challenge of sustaining coral reef resilience. Trends Ecol. Evol. 25:633-642 680 Hutchinson GE (1959) Homage to Santa Rosalia or why are there so many kinds of $681 \quad$ animals? Am. Nat. 93:145-159

682 Johansen JL, Bellwood DR, Fulton CJ (2008) Coral reef fishes exploit flow refuges in 683 high-flow habitats. Mar. Ecol. Prog. Ser. $60: 219-26$

684 Jones GP, McCormick MI, Srinivasan M, Eagle J V (2004) Coral decline threatens fish 685 biodiversity in marine reserves. Proc. Natl. Acad. Sci. 101:8251-8253

686 Keith SA, Baird AH, Hughes TP, Madin JS, Connolly SR (2013) Faunal breaks and 687 species composition of Indo-Pacific corals: the role of plate tectonics, 
environment and habitat distribution. Proc. R. Soc. B Biol. Sci. 280:20130818

689 Kerry JT, Bellwood DR (2012) The effect of coral morphology on shelter selection by $690 \quad$ coral reef fishes. Coral Reefs 31:

691 Kerry JT, Bellwood DR (2015) Do tabular corals constitute keystone structures for 692 fishes on coral reefs? Coral Reefs 34:41-50

693 Kitahara MV, Fukami H, Benzoni F, Huang D (2016) The new systematics of 694 Scleractinia: integrating molecular and morphological evidence. In The 695 Cnidaria, Past, Present and Future (pp. 41-59). Springer International 696 Publishing.

697 Kleypas J, Buddemeier RW, Gattuso J-P (2001) The future of Coral reefs in an age of 698 global change. Int. J. Earth Sci. 90:426-437

699 Laliberté E, Legendre P (2010) A distance-based framework for measuring 700 functional diversity from multiple traits. Ecology 91:299-305

701 Luckhurst E, Luckhurst K (1978) Analysis of the Influence of Substrate Variables on 702 Coral Reef Fish Communities. Mar. Biol. 323:317-323

703 MacNeil MA, Graham NAJ, Cinner JE, Wilson SK, Williams ID, Maina J, Newman S, 704 Friedlander AM, Jupiter S, Polunin NVC, McClanahan TR (2015) Recovery 705 potential of the world's coral reef fishes. Nature 520:341-344 706 Madin EMP, Gaines SD, Madin JS, Warner RR (2010) Fishing indirectly structures 707 macroalgal assemblages by altering herbivore behavior. Am. Nat. 176: 785-801. 708 Madin JS, Anderson K, Andreason M, Bridge TCL, Cairns S, Connolly SR, Darling ES, 709 Diaz M, Falster D, Franklin EC, Gates RD, Hoogenboom MO, Huang D, Keith SA, 710 Kosnik M, Kuo C-Y, Lough JM, Lovelock CE, Luiz O, Martinelli J, Mizerek T, 
711 Pandolfi JM, Pochon X, Putnam HM, Pratchett MS, Roberts E, Stat M, Wallace CC,

712 Widman E, Baird AH (2016a) The Coral Trait Database, a curated database of

713 trait information for coral species from the global oceans. Nat. Sci. Data

$714 \quad 3: 160012$

715 Madin JS, Hoogenboom MO, Connolly SR, Darling ES, Falster D, Huang D, Keith SA,

716 Mizerek T, Pandolfi JM, Putnam HM, Baird AH (2016b) A trait-based approach

717 to advance coral reef science. Trends Ecol. Evol. In press,

$718 \quad$ http://dx.doi.org/10.1016/j.tree.2016.02

719 Manzello DP, Kleypas JA, Budd DA, Eakin CM, Glynn PW, Langdon C (2008) Poorly

720 cemented coral reefs of the eastern tropical Pacific: Possible insights into reef

721 development in a high-CO2 world. Proc. Natl. Acad. Sci. 105:10450-10455

722 McClanahan TR, Graham NAJ, MacNeil MA, Muthiga NA, Cinner JE, Bruggemann JH,

723 Wilson SK (2011) Critical thresholds and tangible targets for ecosystem-based

724 management of coral reef fisheries. Proc. Natl. Acad. Sci. 108:17230-17233

725 McCormick M (1994) Comparison of field methods for measuring surface

726 topography and their associations with a tropical reef fish assemblage. Mar.

$727 \quad$ Ecol. Prog. Ser. 112:87-96

728 Messmer V, Jones GP, Munday PL, Holbrook SJ, Schmitt RJ, Brooks AJ (2011) Habitat

729 biodiversity as a determinant of fish community structure on coral reefs.

$730 \quad$ Ecology 92:2285-2298

731 Mouillot D, Graham NAJ, Villéger S, Mason NWH, Bellwood DR (2013) A functional

732 approach reveals community responses to disturbances. Trends Ecol. Evol.

$733 \quad 28: 167-177$ 
734 Nash KL, Graham NAJ, Wilson SK, Bellwood DR (2012) Cross-scale Habitat Structure

735 Drives Fish Body Size Distributions on Coral Reefs. Ecosystems 16:478-490

736 Newman SP, Meesters EH, Dryden CS, Williams SM, Sanchez C, Mumby PJ, Polunin

737 NVC (2015) Reef flattening effects on total richness and species responses in

738 the Caribbean. J. Anim. Ecol. 84:1678-1689

739 Noonan SHC, Jones GP, Pratchett MS (2012) Coral size, health and structural

740 complexity: effects on the ecology of a coral reef damselfish. Mar. Ecol. Prog. Ser.

$741 \quad 456: 127-137$

742 Perry CT, Murphy GN, Graham NAJ, Wilson SK, Januchowski-Hartley FA, East HK

743 (2015) Remote coral reefs can sustain high growth potential and may match

744 future sea-level trends. Sci. Rep. 5:18289

745 Pinheiro J, Bates D, DebRoy S, Sarkar D (2015) nlme: Linear and Nonlinear Mixed

746 Effects Models. R package version 3.1-120, <URL: http://CRAN.R-

$747 \quad$ project.org/package=nlme>

748 Pittman SJ, Costa BM, Battista TA (2009) Using Lidar Bathymetry and Boosted

749 Regression Trees to Predict the Diversity and Abundance of Fish and Corals. J.

$750 \quad$ Coast. Res. 10053:27-38

751 Polunin NVC, Roberts CM (1993) Greater biomass and value of target coral-reef

752 fishes in two small Caribbean marine reserves. Mar. Ecol. Prog. Ser. 100:167-

$753 \quad 176$

754 Pratchett M, Anderson K, Hoogenboom M, Widman E, Baird A, Pandolfi J, Edmunds

755 P, Lough J (2015) Spatial, Temporal and Taxonomic Variation in Coral

756 Growth-Implications for the Structure and Function of Coral Reef Ecosystems. 
758 Pratchett MS, Hoey AS, Wilson SK, Messmer V, Graham NAJ (2011) Changes in

759 biodiversity and functioning of reef fish assemblages following coral bleaching

$760 \quad$ and coral loss. Diversity 3:424-452

761 R Core Team (2015) R: A language and environment for statistical computing. R

762 Foundation for Statistical Computing, Vienna, Austria. URL http://www.R-

763 project.org/.

764 Roberts CM, Ormond RFG (1987) Habitat complexity and coral reef fish diversity

765 and abundance on Red Sea fringing reefs. Mar. Ecol. Prog. Ser. 41:1-8

766 Rogers A, Blanchard JL, Mumby PJ (2014) Vulnerability of Coral Reef Fisheries to a

767 Loss of Structural Complexity. Curr. Biol. 24:1000-1005

768 Sommer B, Harrison PL, Beger M, Pandolfi JM (2014) Trait-mediated environmental

769 filtering drives assembly at biogeographic transition zones. Ecology 95:1000-

$770 \quad 1009$

771 Stella JS, Pratchett MS, Hutchings PA, Jones GP (2011) Coral-associated

772 invertebrates: diversity, ecological importance and vulnerability to disturbance.

773 Oceanogr. Mar. Biol. An Annu. Rev. 49:43-104

774 Syms C, Jones GP (2000) Disturbance, habitat structure, and the dynamics of a coral-

775 reef fish community. Ecology 81:2714-2729

776 Trebilco R, Baum JK, Salomon AK, Dulvy NK (2013) Ecosystem ecology: size-based

777 constraints on the pyramids of life. Trends Ecol. Evol. 28: 423-431.

778 Williams GJ, Gove JM, Eynaud Y, Zgliczynski BJ, Sandin SA (2015) Local human

779 impacts decouple natural biophysical relationships on Pacific coral 
reefs. Ecography 38: 751-761

781 Wilson SK, Depczynski M, Fulton CJ, Holmes TH, Radford BT, Tinkler P (2016)

782 Influence of nursery microhabitats on the future abundance of a coral reef fish.

$783 \quad$ Proc. R. Soc. B 283: 20160903.

784 Wilson SK, Babcock RC, Fisher R, Holmes TH, Moore JY, Thomson DP (2012) Relative

785 and combined effects of habitat and fishing on reef fish communities across a

786 limited fi shing gradient at Ningaloo. Mar. Environ. Res. 81:1-11

787 Wilson SK, Fisher R, Pratchett MS, Graham NAJ, Dulvy NK, Turner RA, Cakacaka A,

788 Polunin NVC (2010) Habitat degradation and fishing effects on the size

789 structure of coral reef fish communities. Ecol. Appl. 20:442-451

790 Wilson SK, Dolman AM, Cheal AJ, Emslie M, Pratchett MS, Sweatman HPA (2009).

791 Maintenance of fish diversity on disturbed coral reefs. Coral Reefs 28:3-14

792 Wilson SK, Graham NAJ, Polunin NVC (2007) Appraisal of visual assessments of

793 habitat complexity and benthic composition on coral reefs. Mar. Biol.

$794 \quad 151: 1069-1076$

795 Zuur AF, Ieno EN, Elphick CS (2010) A protocol for data exploration to avoid

796 common statistical problems. Methods Ecol. Evol. 1:3-14

797 Zuur AF, Ieno EN, Walker NJ, Saveliev AA, Smith GM (2009) Mixed-Effects Models

798 and Extensions in Ecology with R. Springer, New York, NY 
FIGURES

800 Figure 1 Map of 157 coral reef study sites surveyed between 2010 and 2013 in the

801 Seychelles, Maldives, Chagos Archipelago and Australia's Great Barrier Reef.

802 Underwater visual censuses of both benthic and fish assemblages occurred at each

803 site and points are slightly jittered to reveal sampling effort.

804

805 Figure 2 Benthic characteristics explain variation in reef fish assemblages. Multi806 model averaged parameter coefficients and 95\% confidence intervals are shown for

807 (a) reef fish abundance, (b) biomass and (c) species richness. Positive coefficients

808 indicate a positive relationship between coral and fish characteristics, and negative

809 coefficients indicate a negative relationship. (d), (e), (f) The relationships between

810 structural complexity and reef fish abundance, biomass and diversity, respectively.

811 Blue lines are linear model fits and red lines are LOESS locally weighted smoothers

812 with standard error for each. Shaded points show significant predictors of reef zone

813 and management, as labeled in each legend.

814

815 Figure 3 Influence of structural complexity and coral traits on the functional

816 structure of reef fish assemblages: a) corallivores, b) herbivores, c) invertivores, d)

817 mixed-diet feeders, e) piscivores and f) planktivores. Model-averaged coefficients

818 are shown with 95\% confidence intervals.

819

820 Figure 4 Structural complexity is predicted by coral traits and life histories. (a)

821 Multi-model averaged parameter estimates and 95\% confidence intervals for 
822 predictors of structural complexity. (b) Relationships between significant coral

823 characteristics and structural complexity; blue lines are linear model fits and red

824 lines are LOESS locally weighted smoothers with standard error. The fit in the

825 bottom-right plot between coral cover and structural complexity is from model

826 results presented in Appendix 3.

827 
828 Table 1 Structural complexity and coral assemblage variables of total cover, richness and functional diversity, life histories, 829 and community-weighted trait values considered as predictors of reef fish abundance, biomass and species richness. A 830 description and justification is provided for each variable, as well as the Variance Inflation Factor (VIF) used to assess

831 independence of variables.

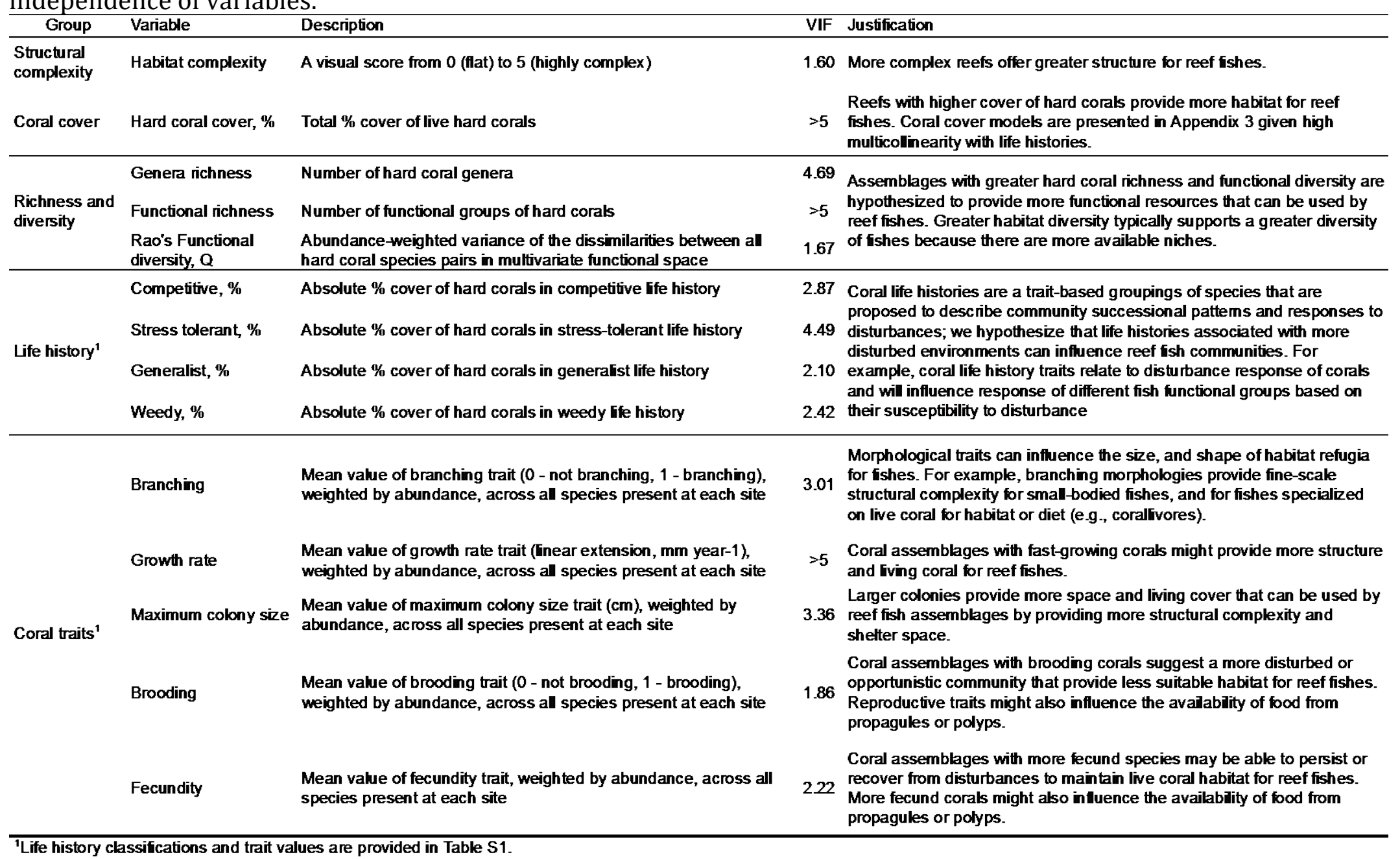


833 Table 2 Top models describing reef fish assemblages, a) total abundance, b) biomass and c) species richness. Check marks 834 indicate presence of variables in the 95\% top model candidate set. Model characteristics (degrees of freedom, df; log

835 Likelihood, logLik; AIC scores corrected for small sample sizes, AICc; and model weight, Weight) are also presented for each 836 model. 
839 Table 3 Top models describing structural complexity of 157 sites in Seychelles, Maldives, Chagos and the Great Barrier Reef.

840 Check marks indicate presence of variables in the 95\% top model candidate set. Model characteristics (degrees of freedom, df;

841 log Likelihood, logLik; AIC scores corrected for small sample sizes, AICc; and model weight, Weight) are also presented for

842 each model.

Diversity Coral life histories

Rank Depth Reef zone Management richness 


\section{ELECTRONIC SUPPLEMENTARY MATERIAL}

846

847

848

849

850

851

852

853

854

855

856

857

858

859

Appendix 1. Sensitivity analysis of survey methods.

Appendix 2. Description of method to visually estimate structural complexity.

Appendix 3. Model comparisons using total coral cover.

Appendix 4. Multi-model analysis of small fish abundance.

Appendix 5. Analysis of six reef fish functional groups.

Appendix 6. Comparison across marine reserves and fished reefs.

Table S1. List of coral genera with life history classifications and trait values. 